\title{
Cytisine and the failure to market and regulate for human health
}

\author{
Paul Aveyard, ${ }^{1}$ Robert West ${ }^{2}$
}

Cytisine is a partial nicotinic agonist found in high concentrations of laburnum, a plant that grows easily in many parts of the world. This makes it inexpensive to manufacture. The drug has been used for many years in eastern Europe as a smoking cessation aid. The drug came to prominence in the Western world following the development of varenicline, a manufactured nicotinic partial agonist, and the publication of a systematic review of cytisine by Etter in 2006. ${ }^{1}$ Etter's review and meta-analysis included several trials published in non-English language journals, most of which were not indexed in Pubmed. The review showed evidence of effectiveness, but the trials had methodological weaknesses that detracted from the evidence. In their article published online, Hajek and colleagues $^{2}$ have updated this review. What has changed?

Since the Etter review, two more studies have been added to the meta-analysis. One of these is a large trial that, had it been done by a pharmaceutical company, might be said to be a typical phase III registration trial. ${ }^{3}$ The data are now stronger that cytisine is effective. Hajek and colleagues ask whether cytisine should now be marketed more widely on the basis of available data. They point out that cytisine has good evidence of efficacy and safety with long postmarketing surveillance in places where it is licensed, with over 4 million users' experience on the European Medicines Authority database. What are the impediments to marketing an apparently safe, effective treatment that is also much cheaper than the alternatives?

For a new drug to receive a marketing license in countries such as the UK, as part of the European regulatory framework, it would normally have had to go through a

\footnotetext{
${ }^{1}$ Department of Primary Care Health Sciences, Radcliffe Observatory Quarter, University of Oxford, Oxford, UK; ${ }^{2}$ Department of Epidemiology and Public Health, University College London, London, UK

Correspondence to Dr Paul Aveyard, Department of Primary Care Health Sciences, Radcliffe Observatory Quarter, Woodstock Road, Oxford OX2 6GG, UK; paul.aveyard@phc.ox.ac.uk
}

process of preclinical testing, dose ranging, then phase II and phase III trials. At least two phase III trials would be required covering different parts of the European region. Given the history of cytisine the regulators would probably waive the need for preclinical testing and dose ranging but would probably want one more trial conducted to the standards known as Good Clinical Practice (GCP). ${ }^{4}$ Only one trial of cytisine meets GCP standards. That said, there appears to be no reason to doubt the results of the other trials or any reason to imagine that the deficiencies in the trials could have led to a spurious result.

In a rational system, a marketing license would be granted on the basis of existing data. The drug is available to buy in Russia and Poland, and on prescription in other former Soviet economy countries. The license could stipulate appropriate postmarketing surveillance, and even one or more phase IV trials.

Failing that, the case for government investment to conduct another phase III trial seems compelling. In the UK, for example, the Government spends many millions of pounds each year on pharmacological treatment for smoking cessation through its publicly funded smoking cessation clinics. An investment of perhaps $£ 2$ million would be enough to save at least 10 times that sum annually, should the trial prove positive, as seems so likely. However, despite this, approaches to the Government have been ignored.

So this leaves the private sector to fund the required trial and bring the drug to market. This has proved more difficult than one would imagine. Those of a more cynical disposition might wonder whether 'big pharma', which would stand to lose considerably if cytisine were marketed, might be playing a role in blocking funding. Or else, it could be that the fact that cytisine is out of patent, and incredibly cheap means that potential investors have failed to see potential for the kind of return they want (probably wrongly in view of the massive market).

If enough people of goodwill continue to push the case for cytisine, it seems likely that the drug will be brought to the market in the whole world eventually. Meanwhile, many people will continue to die from smoking-related disease around the world, when using this drug could have helped them overcome their addiction. In developed countries, health systems continue to pay much more for the alternatives to cytisine at a time of austerity.

This is the Alice in Wonderland world of regulation and capitalism that we live in, but it does not have to be like this. For a small investment in a trial, the world could have a safe and effective medication. The humanitarian case for bringing this drug to market is compelling.

Acknowledgements The work of PA and RW is supported by the UK Centre for Tobacco Control Studies, a UKCRC Public Health Research: Centre of Excellence. Funding from British Heart Foundation, Cancer Research UK, Economic and Social Research Council, Medical Research Council, and the Department of Health, under the auspices of the UK Clinical Research Collaboration, is gratefully acknowledged.

Contributors The article was jointly drafted and edited by both authors.

Funding The work of PA and RW is supported by the UK Centre for Tobacco Control Studies, a UKCRC Public Health Research: Centre of Excellence. Funding from British Heart Foundation, Cancer Research UK, Economic and Social Research Council, Medical Research Council, and the Department of Health, under the auspices of the UK Clinical Research Collaboration, is gratefully acknowledged.

Competing interests PA and RW have undertaken work for the pharmaceutical industry on smoking cessation. RW's institution could stand to gain if cytisine were marketed globally because of intellectual property from the clinical trial he led.

Provenance and peer review Commissioned; internally peer reviewed.

To cite Aveyard P, West R. Thorax 2013;68:989.

Published Online First 1 August 2013

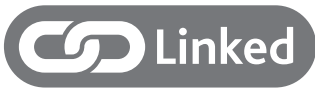

- http://dx.doi.org/10.1136/thoraxjnl-2012-203035

Thorax 2013;68:989.

doi:10.1136/thoraxjn-2013-203246

\section{REFERENCES}

1 Etter JF. Cytisine for smoking cessation: a literature review and a meta-analysis. Arch Int Med 2006;166: 1553-9.

2 Hajek P, McRobbie H, Myers K. Efficacy of cytisine in helping smokers quit: systematic review and metaanalysis. Thorax 2013;68:1037-42.

3 West R, Zatonski W, Cedzynska M, et al. Randomized placebo-controlled trial of cytisine for smoking cessation. New Eng J Med 2011;365:1193-200.

4 ICH GCP 2013 [cited 201357 2013]. http://ichgcp.net/ 